\title{
RESISTANCE TO EXPLOSION ASSESSMENT OF AN ELECTRIC TRANSFORMER BUILDING
}

\author{
LAURE HEUDIER ${ }^{1}$, SEDDIK SAKJI ${ }^{2, *}$, MENAD CHENAF $^{2}$, \\ CHRISTOPHE PROUST ${ }^{1} \&$ JEAN-LUC LACOUR ${ }^{3}$ \\ ${ }^{1}$ Accidental Risk Department, National Institute on Industrial Environment and Risks, France. \\ ${ }^{2}$ Safety of Structures and Fire Department, Scientific and Technical Center of Building, France. \\ ${ }^{3}$ ENEDIS, Electricity Power Grid, France.
}

\begin{abstract}
The ability of technical buildings to resist internal explosions produced by short circuits occurring in electrical transformers is an issue for the public authorities. Even if the probability of such an event is very low, the consequences can be significant and can easily put the surrounding public in danger due the blast, the projection of fragments and to the subsequent very toxic fire. The aim of this article is to investigate the consequences the blast on the structure of the technical building in which the transformer is located. The first part of this study deals with the estimation of the pressure load on the walls of the transformer's building. A complete modelling of the phenomenology is proposed starting from the electrical energy delivered into the arc, its transformation into gases, the efforts applied through the liquid onto the casing of the container, the expansion of the gases inside the building, the blast wave produced and its interaction on the inner walls of the building. In particular, the characteristics (amplitude and duration) of the shock waves are evaluated using the modelling tool 'DIFREX', developed by INERIS. This tool considers the evolution of the shock waves intensity, during their propagation and their reflection on obstacles (like walls). The overpressure signals and their time evolution are calculated according to an optimized spatial discretization in order to get the worst case for the structure. The second part describes the modelling of the building structure using SAP2000 software in order to evaluate its dynamic behaviour and estimate the internal forces induced by the explosion. The structural behaviour depends mainly on the characteristic duration of the overpressure and the overall stiffness of the building. The calculation is performed according a dynamic transient analysis. The results in terms of displacement and the effect on the reinforcement are given.
\end{abstract}

Keywords: building, electric transformer, explosion, FEM modelling overpressure, resistance.

\section{INTRODUCTION}

Explosions of electrical transformers are assumed to be caused by a short-circuit between high-voltage cables. According to information provided by ENEDIS, electric arc is assumed to occur predominantly on the transformer's winding, in the oil bath, producing first a shock wave and then a slower pressure rise, which may ultimately induce the rupture of the transformer (Fig. 1). The nominal power of the electrical transformer under consideration is 70 MVA, its primary nominal voltage is about $200 \mathrm{kV}$ and its secondary nominal voltage is 20 $\mathrm{kV}$. The secondary nominal current is $2500 \mathrm{~A}$ and the secondary resistance of $0.01 \mathrm{ohm}$. At first, is important to estimate the "energy of pressure" released by the electrical arc. This energy represented by a volume of gases at an initial pressure higher than ambient is used to estimate the blast. Sometimes it is referred to as the "Brode energy".

From structural point of view, the loads applied to a structure following an explosion are of a very short duration and of an intensity clearly much higher to the other loads of design (ultimate limit state and serviceability limit state). The fact that the shock induced by blast is applied rapidly implies a relatively high deformation rate which influences the mechanical properties of the materials and the overall behavior of the structure $[1,2]$. The materials laws do not correspond any more to those established under a quasi-static loading. Moreover, the transient loading situation induce a dynamic response of the structure, which results in effects 

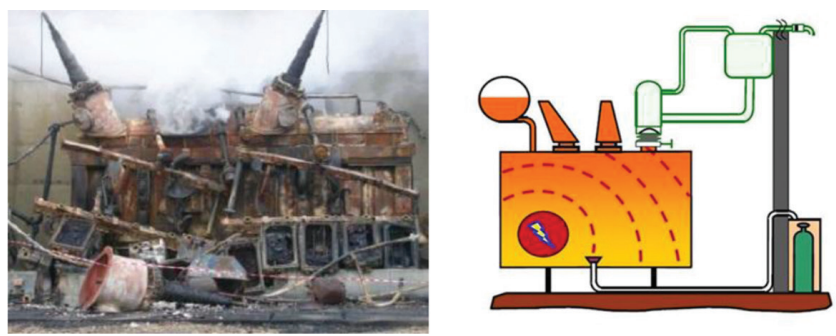

Figure 1: Example of transformer explosion (left) and schema of a transformer and wave propagation in oil bath (right) (source ENEDIS-SERGI).

different from those induced by a static load of the same maximum amplitude [3]. This response is governed by the interaction between the properties of the load and those of the structure. The main parameters of loads given by explosion are the maximum applied pressure, the rise and falling functions of the pressure and the positive phase of duration $\left(\mathrm{t}_{\mathrm{d}}\right)$. The structure is characterized essentially by its properties of mass and stiffness, which define its own period (s) and damping. In this paper, the effect of transformer explosion on the sheltering building will be discussed in section 4 according results given in sections 2 and 3 .

\section{ASSESSMENT OF THE PRESSURE ENERGY}

\subsection{Short circuit through a liquid hydrocarbon}

Specific oils with a high breakdown voltage are used to cool down electrical transformers. It is assumed that because the oil is polluted by corrosion and thermal cycling its dielectric performance degrades so that its mean breakdown voltage drops to $50 \mathrm{kV} / 2.5 \mathrm{~mm}$. Indeed, according to normative method IEC 60156, for a distance of $2.5 \mathrm{~mm}$ between the both electrodes, the breakdown voltage of untreated oil is higher than $30 \mathrm{kV}$, and more than $70 \mathrm{kV}$ for treated oil. Since the nominal voltage is $200 \mathrm{kV}$, the length of the arc gap can theoretically be of $1 \mathrm{~cm}$ (for maximal arc length of $200 \mathrm{kV}$ and breakdown voltage of $50 \mathrm{kV} / 2.5 \mathrm{~mm}: \mathrm{l}=200$ $\mathrm{x} 2.5 / 10 / 50$ ). The arc resistance is often neglected as compared to the transformer's shortcircuit impedance. Then, the maximum electric current is that of the "perfect" short-circuit current (10500 A). Data about arc voltage are scarce in the literature. Measurements [4] reveal that this voltage is about $1000 \mathrm{~V}$ when the current value lies between $13000 \mathrm{~A}$ and 35000 A (Table 1).

If this value is used, the electrical power dissipated by the arc $Q_{\text {arc }}$ is about $10 \mathrm{MW}$. The dissipated energy $E$ depends on the duration $t$ of the short circuit: $\mathrm{E}=\mathrm{Q}_{\mathrm{arc}} \mathrm{x}$.

Experiments reveal that the measured electric energy is only $25 \%$ of the predicted value obtained from the arc power and duration, certainly because the electric arc is not stable and may extinguish during the test. However, in safety studies, the nominal value is used.

Table 1: Experimental measurements [4].

\begin{tabular}{lllll}
\hline Maximal Current $(A)$ & 34476 & 14476 & 13121 & 31783 \\
Maximal Voltage $(V)$ & 1034 & 979 & 860 & 923 \\
Arc Energy $(K J)$ & 460 & 212 & 208 & 414 \\
\hline
\end{tabular}


The maximum duration of the short circuit is restricted by the activation time of the electrical protections (set to $700 \mathrm{~ms}$ ), leading to a nominal electrically dissipated arc energy of $7 \mathrm{MJ}$.

Experiments on electrical discharges between two electrodes in water reveal that arcing in water begins with the production of a gas bubble on one electrode, using a part of electrical energy [5]. Then, an electric arc crosses the electrode gap through the bubble and produces a shock wave. This shock wave propagates in the liquid at the sound speed. Cole [6] reports that the volume of the bubble and the pressure increase with the electrical energy.

\subsection{Underwater explosions}

The phenomenology of underwater explosions is similar to underwater gas explosions. The maximal overpressure $\left(\mathrm{P}_{\max }\right.$, in bar) produced by the underwater explosion induced by the detonation is given according the equation:

$$
P_{\max }=540 \cdot\left(\frac{M_{T N T}^{1 / 3}}{R}\right)^{1,13}
$$

Where $M_{T N T}$ is the mass of the equivalent TNT given in $\mathrm{kg}$ and $\mathrm{R}$ is the distance from the explosion source in $\mathrm{m}$.

This formula is used to estimate the "energy of pressure" responsible for the pressure effects measured during experiments performed to assess this phenomena [6]. The main results are reported on Fig. 2. The value of $\mathrm{M}_{\mathrm{TNT}}$ enabling the theoretical curve to go through the points is estimated for each sets of points. The "energy of pressure" (Eb = Brode energy) is $\mathrm{M}_{\mathrm{TNT}} \mathrm{x}$ TNT Heat of combustion (4600 $\mathrm{kJ} / \mathrm{kg}$ of TNT). Clearly a very small part (about 5 $\%$ ) of the energy $\mathrm{E}$ is used to produce the shock wave propagating through the liquid. This is very well known for high explosives and means that an important part of the delivered energy is converted into thermal energy and gas production (vaporization, pyrolysis). A larger part would be released in air and important overpressure level can be reached close to the bubble (several thousands of bars).

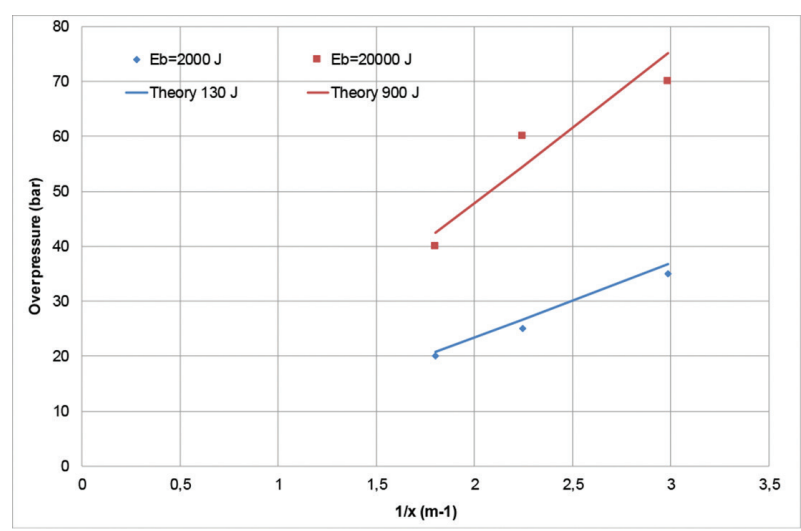

Figure 2: Evolution of overpressure (bar) depending on reduced distance $\left(\mathrm{m}^{-1}\right)$ for an underwater explosion, measurements and calculations from optimized pressure energy 


\subsection{Modelling}

To model this, it is assumed that the arc energy is released homogeneously into the gaz bubble, and that the energy for vaporization of the liquid close is transmitted by conduction only (too short duration for convection to appear).

$$
M_{\text {bulle }} \cdot \bar{C} p \cdot \frac{d T_{\text {bulle }}}{d t}=\dot{Q}_{\text {arc }}-\underbrace{A_{\text {bulle }} \cdot \xi \cdot \sigma_{\text {Boltzmann }} \cdot\left(T_{\text {bulle }}^{4}-T_{\text {liq }}^{4}\right)}_{\text {radiation }}-\underbrace{\dot{m}_{\text {bulle }} \cdot\left(L_{\text {vap }}+\bar{C} p \cdot\left(T_{\text {bulle }}-T_{\text {liq }}\right)\right)}_{\text {vaporization/dissociation }}
$$

Bubble temperature $T_{\text {bulle }}$ can be several tens of thousands of degrees. Locally at least, a plasma will be formed, composed of light elements (atoms or simple molecules) resulting from thermal cracking. Heat capacity $(\mathrm{Cp})$ includes liquid dissociation energy. This process depends on temperature and is not a phase change. Data on plasmas [7], reveal that, for high temperature ( 5000 to $10000 \mathrm{~K}$ ), radiation is not a loss, because it is absorbed by the oil. Then, most part of the released energy is used in liquid vaporization via conduction, and reads:

$$
V_{\text {bulle }}=\int_{\frac{P}{r_{g}}}^{\lambda_{g}} \cdot \frac{4 \cdot \pi \cdot r_{\text {bulle }}}{L_{\text {vap }}} \cdot \frac{\dot{Q}_{\text {arc }}}{4 \cdot \pi \cdot r_{\text {bulle }}^{2}} \cdot \frac{r_{\text {bulle }}}{\lambda_{g}} \cdot \frac{L_{\text {vap }}}{\bar{C} p} \cdot d t=\frac{E}{\frac{P}{r_{g}} \cdot \bar{C} p}
$$

Oil chemical formula is typically $\mathrm{C}_{\mathrm{n}} \mathrm{H}_{2 n}$ with $\mathrm{n}>>10$, and the heat of vaporization amounts about $150-200 \mathrm{~kJ} / \mathrm{kg}$. Using the formula requires an estimation of $\mathrm{r}_{\mathrm{g}}\left(=\mathrm{R}_{\mathrm{gp}} / \mathrm{MM}\right.$ with $\mathrm{R}_{\mathrm{gp}}$ is the perfect gas constant and MM is the molar mass of plasma) and $\mathrm{Cp}$, which are very temperature dependent:

- between 2000 et $5000 \mathrm{~K}$, plasma is essentially composed of $\mathrm{H}_{2}$ and $\mathrm{CH}_{4}$, with tending to the molar mass of methane (16 g/mole),

- between $7000 \mathrm{~K}$ and $15000 \mathrm{~K}$, plasma will be composed of $2 / 3$ of free $\mathrm{H}$ atoms and $1 / 3$ of free $\mathrm{C}$ atoms, suggesting a molar mass $\mathrm{MM}$ of about $5 \mathrm{~g} / \mathrm{mole}$,

- above $15000 \mathrm{~K}$, plasma is highly ionized and is composed of electrons (zero mass) and atomic species (of the same nature and in the same proportions as above), so it can be assumed that $\mathrm{MM}=5 / 2=2.5 \mathrm{~g} / \mathrm{mole}$.

\section{Estimation of the gas volume produced and of $\mathbf{E b}$}

The evolution of the bubble volume depending on arc energy can be estimated according to the blue line of Fig. 3 and it is strongly dependent on Cp and MM. These latter are estimated on the basis of the mean temperatures between the middle of the bubble (around 5000 $10000{ }^{\circ} \mathrm{K}$ according to calculations for plasma) and the vaporization point (on the bubble boundary). An analytic estimation of the bubble volume is possible choosing values of MM and $\mathrm{Cp}$ corresponding to a temperature between 3000 and $4000 \mathrm{~K}$, respectively $16 \mathrm{~g} / \mathrm{mole}$ and $3000 \mathrm{~J} / \mathrm{kgK}$ (red dashed line on Fig. 3), and at a pressure close to the atmospheric one:

$$
V=1,8 \times \frac{E}{1000000}\left(\mathrm{E} \text { in } \mathrm{J} \text { and } \mathrm{V} \text { in } \mathrm{m}^{3}\right)
$$

The Fig. 3 gives a comparison between these estimations and the experimental data [4].

Actually, the power is certainly not constant so that some upper limit is found. The theoretical analysis doesn't suggest any upper limit for the gas production rate (since all the arc 


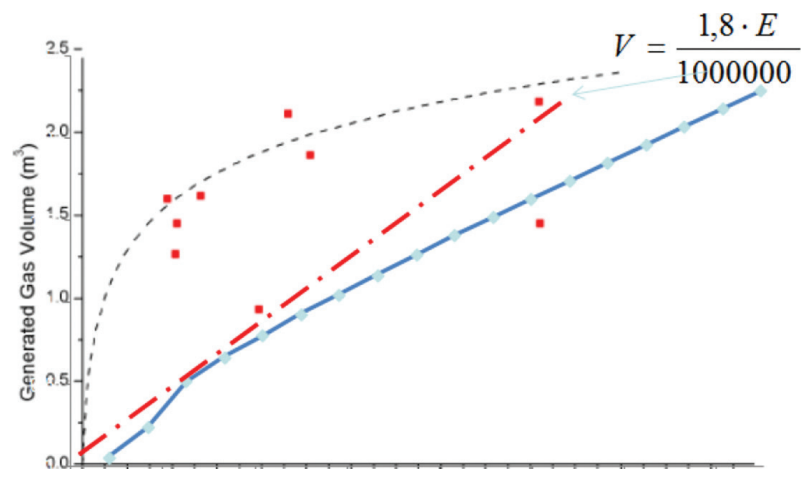

Figure 3: Evolution of produced gas volume depending on arc energy (black curve and experimental points from [4], red dashed and blue lines from present work).

energy is used for liquid vaporization). Then, for the arc energy considered here (7 MJ), it is safer to consider this relation, without upper limit.

When released to air, the energy available to produce a pressure wave (Eb), can be estimated as done with high explosives. The gas expansion energy corresponds to the energy of the fully expanded bubble (then at the atmospheric pressure) in the liquid:

$$
E_{b}=P \cdot V=0,18 \cdot E
$$

It corresponds then to only $18 \%$ of $\mathrm{E}$. The other part is used to vaporize the oil. Since only $5 \%$ of $\mathrm{E}$ is used to produce a shock wave inside the liquid, the remaining part (13\%) is used to expand and pressurize slowly the bubble. But this extra energy will be available to produce a blast wave in the inner building volume after the transformer's disruption. So, for the specific transformer under consideration, values of $\mathrm{E}=7 \mathrm{MJ}, \mathrm{Eb}=1.26 \mathrm{MJ}$ and $63 \mathrm{~kJ}$ are used to propagate a shock wave into the liquid.

\section{OVERPRESSURE EFFECTS ASSESSMENT}

\subsection{Modelling of the shock}

Using eqn (4), the shock wave amplitude propagating in the liquid can be evaluated (Fig. 4). Pressure of hundreds of bars can be produced at a distance of $50 \mathrm{~cm}$ to $1 \mathrm{~m}$ from the arc.

Then the mechanical disruption of the casing is probable especially when the arc occurs close to it. In this case, the gas bubble will immediately burst outside, in the open air and all the available "energy of pressure" (Eb) will participate to the formation of the blast wave propagating in the building. The semi analytical tool DIFREX developed by INERIS [8] is used to assess the blast wave propagation. The characteristics of the blast wave are that of a classical blast wave from explosives (or more precisely of instantaneous releases of pressure) given out from the well-known Hopkinson model, also used by TNO [9] and Baker [10]. Explosives, like TNT, are the closest real energy sources to the theoretical point source considered in the Hopkinson model, because their pressure energy is equal to their combustion energy. The following curve (Fig. 4R) represents the evolution of the overpressure produced by the explosion of a certain mass of TNT $(Q)$ with the reduced distance $X / Q^{1 / 3}$, and results of tests performed in INERIS, consistent with the predictions. 

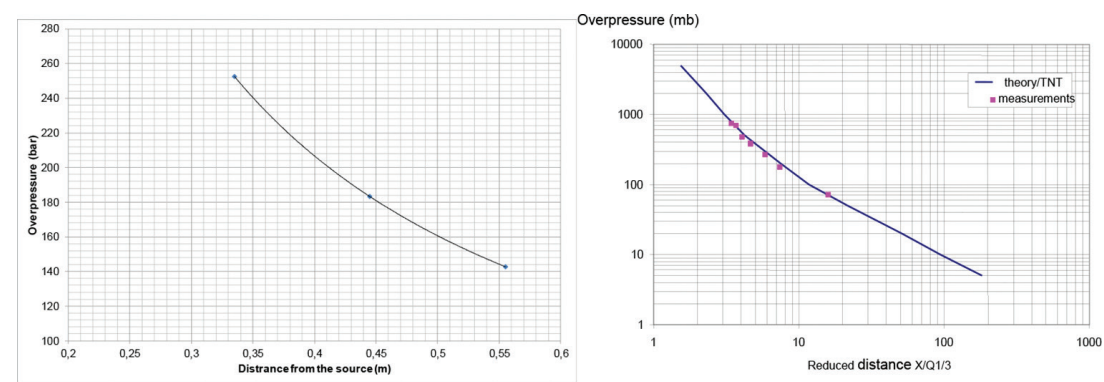

Figure 4: left: Predicted overpressure in oil, close to the arc, right: evolution of the overpressure with the reduced distance in air

When a pressure wave propagates in a building and impinges on a wall, a wave reflection occurs inducing a change in the overpressure magnitude. It is calculated using DIFREX thanks to the shock wave theory [11] under the following simplifying assumptions:

- only the component of the shock wave velocity perpendicular to the wall is transformed in overpressure (regular reflection),

- the Mach reflection phenomenon is neglected.

Thus, when an overpressure wave with a magnitude $\mathrm{P}_{1, \mathrm{n}}$ impacts normally a wall, it is reflected as a pressure wave with a magnitude $\mathrm{P}_{2, \mathrm{n}}$ according to eqn (6).

$$
\frac{P_{2, n}-P_{0}}{P_{1, n}-P_{0}}=\frac{(2 \mu+1) \frac{P_{1, n}}{P_{0}}+1}{\mu \frac{P_{1, n}}{P_{0}}+1}
$$

with $\mu=(\gamma-1) /(\gamma+1)$ and $\gamma$ the heat capacity ratio of the gas in which the wave propagates (air in this study, so $\gamma=1.4$ ). Calculations with DIFREX are consistent with experimental data, even if they are somewhat conservative [12].

For the present transformer configuration, $\mathrm{Eb}=1.26 \mathrm{MJ}$ produces a propagating wave and a static overpressure due the expansion of the bubble inside the building. Up to 200 mbar, blast wave is produced less than $5 \mathrm{~m}$ from the transformer, and the final static overpressure in the building $\Delta \mathrm{P}_{\text {bat }}$ is very small (around 5 mbar) due to the big available volume $\mathrm{V}_{\text {bat }}$ $\left(1230 \mathrm{~m}^{3}\right)$ :

$$
\frac{\Delta P_{b a t} V_{b a t}}{\lambda-1}=E_{\text {exp }}=0.18 \cdot E
$$

\subsection{Spatial average pressure applied on each wall and duration}

A pressure wave can be viewed as a spherical shell of pressurised gases growing in size with the time. As said before, the Hopkinson law are used to calculate the characteristics of the shell (overpressure, thickness). When the shell interacts with a wall, it applies on the surface a pressure load corresponding in size with the intersection of the shell with the front surface 
of the wall and in intensity with the reflected wave. As the shell develops, this intersection changes (Fig. 5) and ultimately leaves the wall. As a result, the average effort applied changes with time and finally disappears. To model this average effort, an average pressure applied on all the surface of the wall corresponding to this effort is calculated at each time step and a spatial discretization (Fig. 6) of the walls is carried out.

Walls are decomposed in several panels, on which overpressure signals are calculated. The overpressure signal obtained on the nearest panel (around $5 \mathrm{~m}$ from the transformer) are shown in Fig. 6. The maximum overpressure is locally very high (around 400 mbar), but its duration is very low, so that the impulse is also low, about 20 Pa.s.

\section{ASSESSMENT OF THE BUILDING BEHAVIOR}

Exposed to a shock wave, a structure presents a dynamic behavior whose description depends essentially on the natural period of the structure $(\mathrm{T})$ and the characteristic duration of the blast $\left(\mathrm{t}_{\mathrm{d}}\right)$. Three regimes of response can be distinguished for different ratios of $\frac{t_{d}}{T}$; impulsive regime, quasi static regime and dynamic regime.

Impulsive regime: $\frac{t_{d}}{T}<0.4$

This mode is characterized by a very short dynamic loading time with respect to the natural period of the structural element. The impulsive regime corresponds to the transfer of the

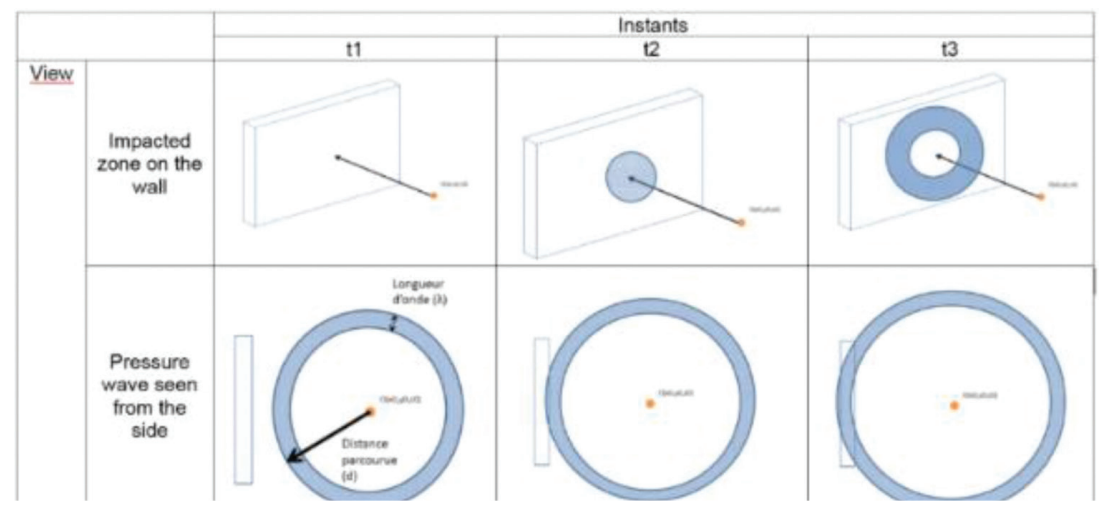

Figure 5: Time evolution of the wall loading.

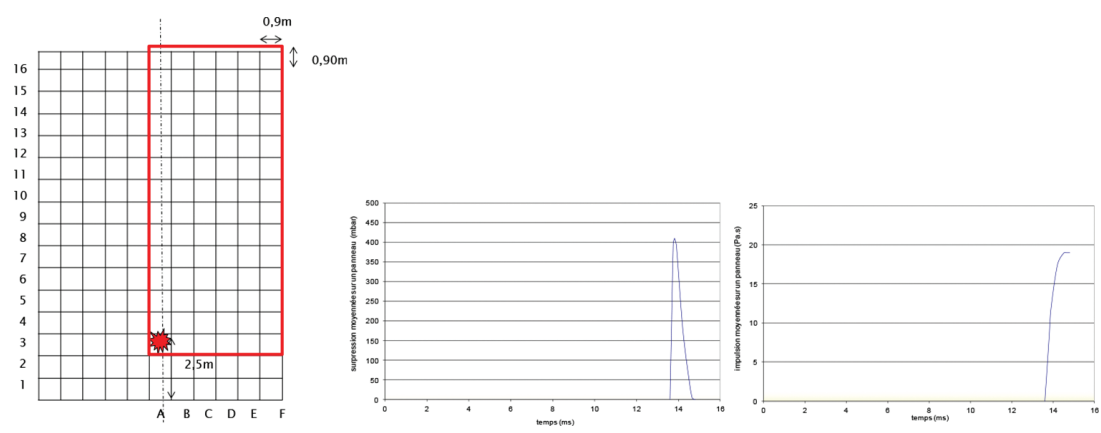

Figure 6: Discretization of a $10 \mathrm{~m}$ long and $14 \mathrm{~m}$ high wall with location of the explosion (left) and Overpressure and impulse calculated on the nearest panel A3 (right). 
energy of the wave into kinetic energy. The value of the transmitted impulse is the predominant factor for evaluating the dynamic behaviour of the structure. Thus, it is not necessary to have an important precision on the shape of the wave, nor on the peak of overpressure. Most of the structural deformation occurs after the applied load is cancelled. The almost instantaneous application of a pulse to the system amounts to providing it with an initial velocity, and therefore a kinetic energy. The maximum deformation of the structure occurs then when the internal energy of the structure is equal to the kinetic energy.

\section{Mode quasi-statique: $t_{d} \gg T$}

When the duration of the positive pressure is considerably much greater and longer than the natural period to the system, it is called quasi-static loading. In this case, the applied load remains almost constant until the maximum displacement is reached. The duration does not influence the response of the structure as soon as the maximum displacement is reached. The quasi-static mode corresponds to a transfer of energy from excitation to deformation energy. Knowledge of the associated peak is essential for the quasi-static response mode. The maximum displacement is obtained when the work given by the external force (constant during the characteristic period $t_{d}$ ) is equal to the internal energy of the deformation.

\section{Mode dynamique $0.4<\frac{t_{d}}{T}<\mathbf{2}$}

Dynamic response regime is an intermediate mode and is more complex to analyse. It requires considering the transfer of energy into kinetic energy, but also which is related to the energy of deformation. Consequently, a transient calculation must be carried out if it is desired to have a not too conservative evaluation of the structure behaviour with respect to the excitation under consideration.

The analysis of the transformer building is presented in the following parts.

\subsection{Model and hypothesis}

A finite element modelling was performed with SAP2000 software on the basis of the design plan of the transformer building (part (a) of Fig. 7). The building walls and panels were modeled considering shell elements. The mechanical properties of concrete and rebars are shown in part (b) of Fig. 7. Apart from the automatically calculated gravity load based on the concrete density, permanent and service load are applied to the structure (see part c of Fig. 7). The overpressure generated by the explosion was the subject of a detailed study (see $\S 3$ ). The main results have been formulated in the form of signals impacting a vertical panel and a horizontal panel. The panels were discretized according to a mesh chosen in such a way that a signal is relatively the same in each one of the meshes. A set of 78 signals were provided for each of the vertical panels and two signals for the horizontal panel. For vertical panels, the pressure is $40 \mathrm{kPa}$ for the zone closest to the impact and $6 \mathrm{kPa}$ for the furthest zone. The durations range from $0.5 \mathrm{~ms}$ to $5 \mathrm{~ms}$. For the horizontal panel, the maximum pressure is of 19 $\mathrm{kPa}$ with a duration of $2 \mathrm{~ms}$. Figure 8 shows, by way of indication, the pulses transmitted to the various elements of the column A of the vertical panel (see Fig. 6 for the discretisation into columns and rows). Those of the other columns and walls have the same typology except that they are slightly time shifted. Figure 9 shows the pressure signals transmitted to the +10.35 m horizontal slab.

The adopted solver corresponds to a modal temporal resolution with a modal basis constituted by eigenmodes identified to correspond to $90 \%$ of the embedded modal mass. 


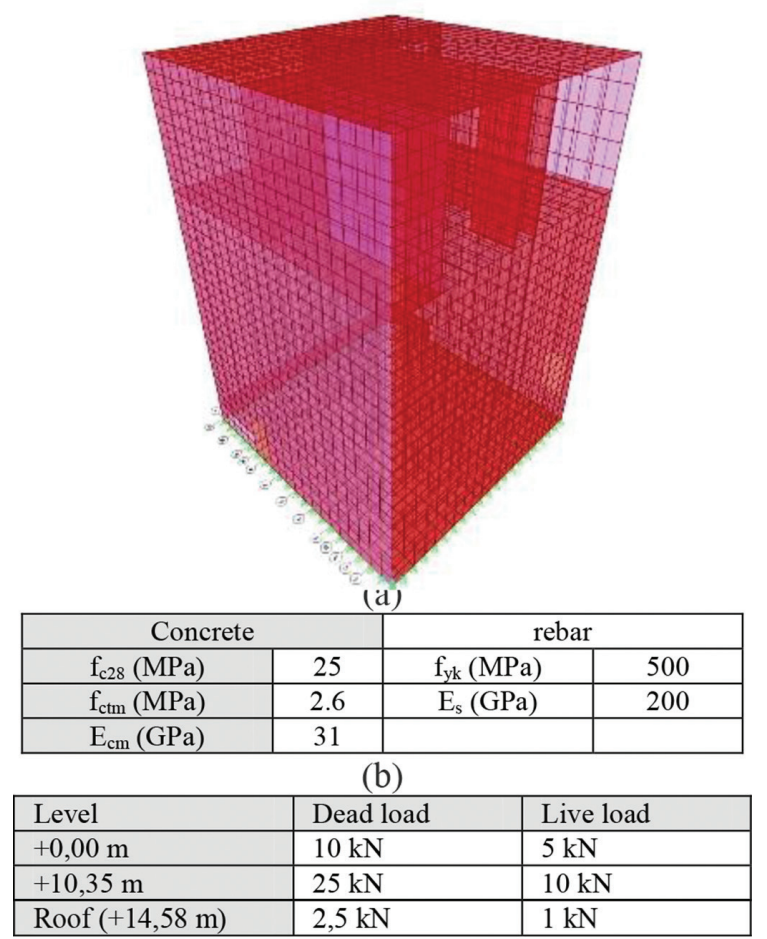

(c)

Figure 7: (a) Numerical 3D model; (b) mechanical characteristics; (c) applied loads.

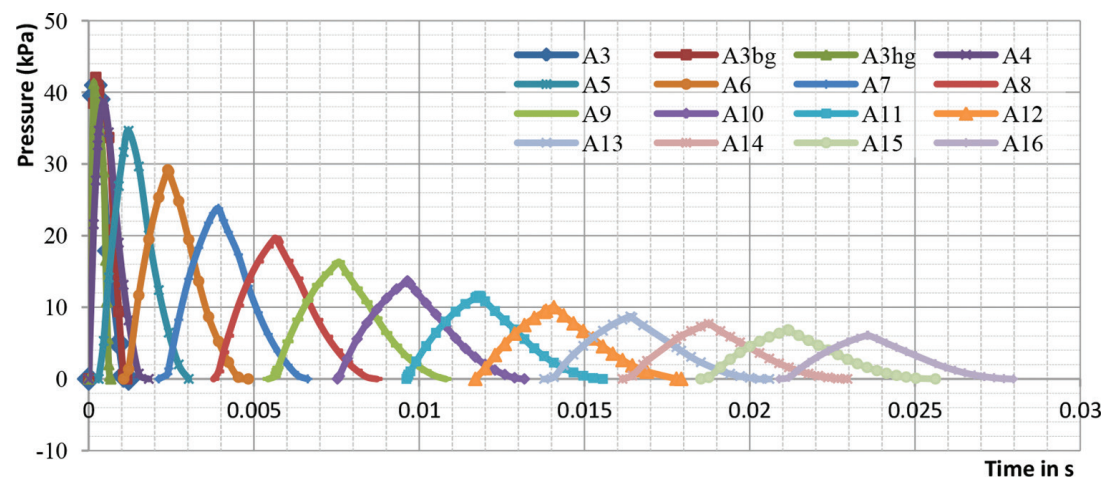

Figure 8: Pressure load as a function of time taken into account for vertical panels.

\subsection{Results}

The extraction of the eigenmodes was done in such a way that a modal participation factor of $90 \%$ is obtained. For this matter, a set constituted by the first 200 modes was necessary to construct the modal basis of analysis. Table 2 shows the modal synthesis used for numerical simulations. The first and the 5th eigenmodes shape are given in the Fig. 10. The fundamental period is $0.0836 \mathrm{~s}$ and the period of the last mode of the mode basis is $0.0066 \mathrm{~s}$. 


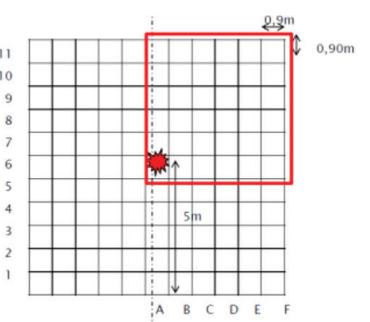

(a)

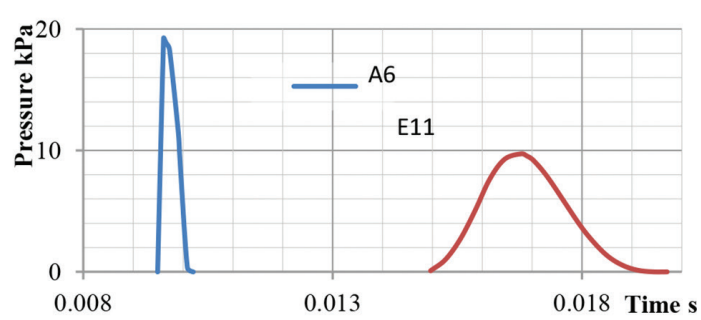

(b)

Figure 9: Pressure load as a function of time for horizontal panels (10.35 m).

Table 2: Modal load participation factor.

\begin{tabular}{lllll}
\hline OutputCase & ItemType & Item & Static & Dynamic \\
\hline Text & Text & Text & Percent & Percent \\
MODAL & Acceleration & UX & 99.9217 & 87.2858 \\
MODAL & Acceleration & UY & 99.95 & 90.9076 \\
MODAL & Acceleration & UZ & 99.6873 & 87.9319 \\
\hline
\end{tabular}
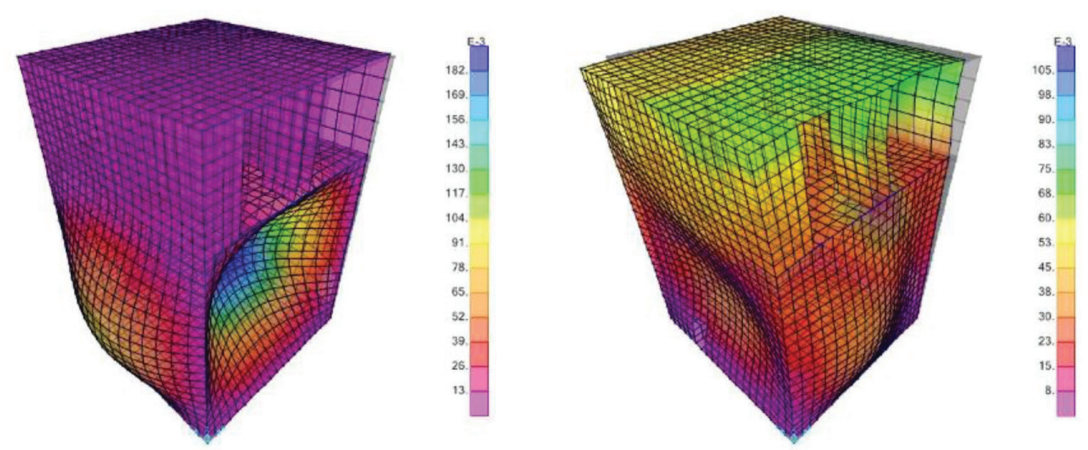

Figure 10: First and 5th Eigen modes $\left(\mathrm{T}_{1}=0.083\right.$ and $\left.\mathrm{T}_{5}=0.063\right)$.

The deformation of the structure at the moment when the last one is the more significant over the whole building is given in the part (a) of the Fig. 11. The part (b) of the Fig. 11 shows the evolution of the out-of-plane displacement as a function of time at some points of the facade. The maximum out of plane displacement of the building is about $2 \mathrm{~mm}$.

\subsection{Discussion}

The evolution of the out-of-plane displacement as a function of time shows that the structure goes in a deformation mode governed by an impulsive regime (see §2.1). This is consistent with the results in terms of modal synthesis about the characteristic period of the pulse. Indeed, considering the set of pulses applied to the structure, the characteristics of their outputs $\left(\mathrm{t}_{\mathrm{d}}\right)$ vary from 0.05 to $5 \mathrm{~ms}$. Moreover, the fundamental period of the local transformer is $0.0836 \mathrm{~s}$ and that of the 50th mode is $0.0166 \mathrm{~s}$ (the first 50 modes are the more relevant). It 


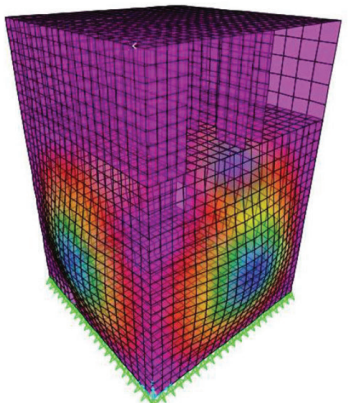

(a)

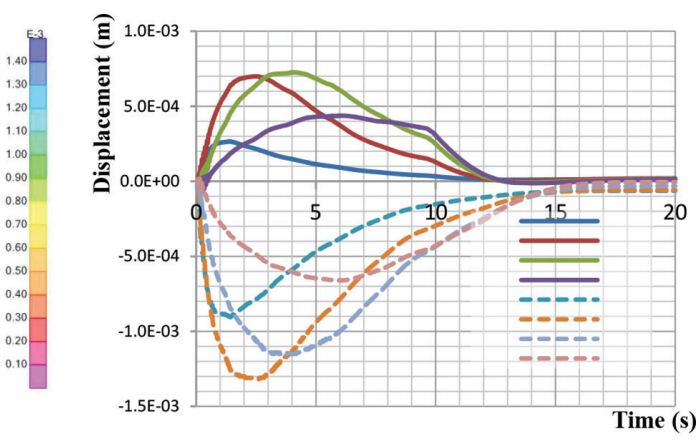

(b)

Figure 11: (a) Deformation of the structure at $3 \mathrm{~s}$; (b) Displacement as a function of time.

can be seen that the maximum ratio between the characteristic periods of the pulses and the local periods of the local transformer is 0.29 . This value is less than 0.4 , the representative value of the change from impulse regime to the dynamic one.

The aim is to verify the relevance of the results in terms of deformation obtained in the previous section, we consider a simply supported panel of dimension $10 \times 10 \mathrm{~m}^{2}$ subjected to a pressure of $40 \mathrm{kPa}$. The calculation of the deformation of the panel in question under the applied load gives a value of $22 \mathrm{~mm}$ [13-15]. Considering that this panel is subjected to a pulse of the same intensity $(40 \mathrm{kPa})$ with a characteristic duration $\mathrm{t}_{\mathrm{d}}$ of $1 \mathrm{~ms}$ corresponding to the signal A3 (see Fig. 8), the maximum dynamic load factor $\left(\mathrm{DLF}_{\max }\right)$ is given according:

$$
D L F_{\text {max }}=\frac{x_{\text {max }}}{x_{\text {stat }}}=\frac{1}{2} \omega t_{d}=\frac{1}{2} \frac{2 \pi}{T} t_{d}=\frac{\pi}{0,08360} 0,001=0,03
$$

Thus, the maximum displacement under this pulse is $0.814 \mathrm{~mm}(0.037 \mathrm{x} 22 \mathrm{~mm})$. This value should be compared to the maximum displacement found in the previous section (see Fig. 11). Obviously, the overall behavior is much more complex since it is governed by a set of pulses of different characteristic durations applied on the walls of the building. This result allows, however, to have an order of magnitude and verify the relevance of simulations.

The calculation of the reinforcement (rebars) of the walls is performed according to the maximum membrane forces and the flexural moments found as a result of the transient dynamic analysis. The maximum ratio found is about $4 \mathrm{~cm}^{2} / \mathrm{m}$.

\section{CONCLUSION}

The paper provides a study case for the assessment of resistance to explosion of an electrical transformer's building. It is based on an explicit identification of the pressure transmitted to the building at every location. The field of overpressure as a function of time is calculated using the DIFREX tool taking into account the electrical energy transformed into pressure. The modelling of the structure using the software SAP2000 according a Modal transient analysis gives the strain and the stress field into the wall panels and then the design of the structural elements under shock waves. 


\section{REFERENCES}

[1] Yandzio, G., Protection of Buildings Against Explosions, SCI publication, Bershire, UK, 1999.

[2] UFC 3-340-02, Unified Facilities Criteria (UFC, Structures to resist the effects of accidental explosions, 2008, Change 2, National Technical Information Service, Washington, DC, 2008.

[3] Cormie, D., Mays, G. \& Smith, P., Blast Effects on Buildings, 2nd edn., Thomas telford, 2009.

[4] Muller S. \& Brady R., Prevention of transformer tank explosion. Part 1: experimental tests on large transformers. ASME Pressure Vessels and Piping Division Conference, 27-31 July, Chicago, Illinois, USA, 2008.

[5] Touya, G., Contribution à l'étude expérimentale des décharges électriques dans l'eau et des ondes de pression associées. Réalisation d'un prototype industriel $100 \mathrm{~kJ}$ pour le traitement de déchets par puissances électriques pulsées, 2005.

[6] Cole, R.H., Underwater Explosions, Princeton University Press, Princeton, NJ, 1948.

[7] Cressault, Y., Propriétés des plasmas thermiques dans des mélanges argonhydrogène-cuivre. Université Paul Sabatier Toulouse, 2001.

[8] Heudier, L., Proust, Ch. \& Couillet J.-C., Capacités de gaz sous pression - risques d'explosion, Préventique Sécurité juillet-août, 2006.

[9] T.N.O., Methods for the Calculation of the Physical Effects of the Escape of Dangerous Material (Yellow Book), Committee for the prevention of Disasters, 1997.

[10] Baker, W.E., Cox, P.A., Westine, P.S., Kulesz, J.J. \& Strehlow, R.A., Explosion Hazards and Evaluation, Elsevier, New York, NY, 1983.

[11] Wright, J.K., Shock Tubes, John Wiley and sons, Londres, 1961.

[12] Heudier, L., Les éclatements de réservoir - Phénoménologie et Modélisation des effets, rapport INERIS $\Omega 15,2013$.

[13] André COIN et Philippe BISCH, Conception des murs en béton selon les Eurocodes, Principes et application, Presse de l'école nationale des Ponts et Chaussées, 2008.

[14] NF EN 1992-1-1 Eurocode 2: Design of concrete structures-Part 1-1: General rules and rules for buildings - October 2005 .

[15] NF EN 1992-1-1/NA - Eurocode 2 : conception et calcul des structures en béton - Partie 1-1 : Règles générales et règles pour les bâtiments - Annexe Nationale à la NF EN 1992-1-1»- mars 2007. 